\title{
IN VIVO AND IN VITRO DEVELOPMENT OF SOMATOSTATIN- LIKE-IMMUNOREACTIVITY IN THE PERIPHERAL NERVOUS SYSTEM OF QUAIL EMBRYOS ${ }^{1}$
}

\author{
JOSÉ E. GARCIAA-ARRARÁS, ${ }^{2}$ MARCELLE CHANCONIE, AND JOSIANE FONTAINE-PÉRUS \\ Institut d'Embryologie du Centre National de la Recherche Scientifique et du College de France, 94130, \\ Nogent-sur-Marne, France
}

Received July 29, 1983; Revised December 7, 1983; Accepted December 13, 1983

\begin{abstract}
The appearance and development of somatostatin-like immunoreactivity (SLI) in the peripheral nervous system of quail embryos were studied using radioimmunoanalysis and immunocytochemistry. In vivo, no SLI is observed in neural crest cells before or during migration. SLI appears between days 3 and 4 of incubation in sympathetic ganglia, immediately following ganglion formation, and between days 4 and 5 of incubation in the adrenal gland, soon after the adrenal gland primordium first appears. The development of SLI in the adrenal gland differs from that in the sympathetic ganglia. While in the former the amount of SLI and the number of SLI-containing cells increase as the embryo ages, in the sympathetic ganglia the amount of SLI and the percentage of SLI-containing cells decrease.

When migrating neural crest cells are obtained from the sclerotomal part of 3-day embryos and grown in culture, they first display SLI after $48 \mathrm{hr}$, and the amount of SLI increases thereafter. When the sympathoadrenal precursors are removed at 4 days of incubation and grown in vitro, SLI appears after $24 \mathrm{hr}$ in culture and increases during the next few days.

Our results demonstrate that SLI is present very early in the quail embryo and that its appearance parallels the differentiation of neural crest cells into autonomic sympathetic ganglionic cells. We also show that the differentiation of neural crest into SLI-containing cells can be reproduced in culture, thus permitting the study of peptide production and expression in vitro.
\end{abstract}

During embryogenesis, neural crest cells migrate along definite pathways and differentiate into various types of neuronal and non-neuronal tissues, including most of the peripheral nervous system (see Hörstadius, 1950; Weston, 1970; Le Douarin, 1980, 1982). To the multiplicity of functions displayed by the cell types that emerge from the neural crest corresponds an array of characteristic biochemical specializations. Thus, many crest derivatives synthesize and store specific neurotransmitters or neuromodulators.

${ }^{1}$ We wish to thank Prof. N. Le Douarin for her advice and support and Dr. Julian Smith for his help and valuable comments on the manuscript. We are grateful to Dr. M. Fauquet for her guidance in culturing cells and to Ms. C. Breant and G. Gateau for their technical assistance. We acknowledge Dr. F. Dray for introducing us to radioimmunoanalysis techniques and Dr. P. Brazeau for his gift of antiserum. This work was financially supported by grants from the Centre $\mathrm{Na}$ tional de la Recherche Scientifique, Ministère de l'Industrie et de la Recherche, Institut National de la Santé et de la Recherche Médicale, and National Institutes of Health. J. E. G.-A. is the recipient of a postdoctoral fellowship from the American Physiological Society, Porter Development Committee.

${ }^{2}$ To whom correspondence should be addressed.
Tissue interactions and environmental factors are involved in this differentiation process. In vivo experiments have shown that migrating neural crest cells lack adrenergic properties and that their acquisition of these features later in development depends on the cellular environment they contact (Le Douarin et al., 1981; see also Patterson, 1978). In vivo and in vitro studies have demonstrated the role of certain tissues encountered by migrating neural crest cells, such as the somitic mesoderm, the ventral neural tube, and the notochord, which elicit the differentiation of neural crest cells into catecholaminergic cells (Cohen, 1972; Norr, 1973; Teillet et al., 1978; Fauquet et al., 1981). Recently, Fauquet et al. (1981) have shown that when migrating crest cells are grown in vitro, the development of either cholinergic or adrenergic properties can be influenced by the age of the neural crest cells, by the addition of other cell types to the culture, and by factors present in the medium.

To date, most of the studies on neural crest differentiation into neurotransmitter-containing cells have focused on acetylcholine and catecholamine production. An exception is the examination by Maxwell et al. (1982) of the synthesis of other putative neurotransmitters in 
neural crest cultures. Under their culture conditions, only acetylcholine, noradrenaline, and dopamine were synthesized. No significant synthesis of serotonin, GABA, or octopamine was found.

Various neuropeptides, thought to have a neurotransmitter or neuromodulator role, are made by neurons derived from the neural crest (Hökfelt et al., 1980; AyerLe Lievre and Fontaine-Pérus, 1982). Somatostatin (SRIF, somatotropin release-inhibiting factor), a tetradecapeptide first isolated from extracts of sheep hypothalamus (Brazeau et al., 1973), has been found in various species, both in neural crest-derived tissues and in other neuronal and non-neuronal cells (Hökfelt et al., 1975a; Alumets et al., 1977; Patel and Reichlin, 1978; Fontaine-Pérus, 1980). In the peripheral nervous system, somatostatin-like immunoreactivity (SLI) has been detected by immunocytochemistry in the adrenal medulla of guinea pigs and humans (Lungberg et al., 1979), in some adrenergic prevertebral sympathetic neurons of the guinea pig and rat (Hökfelt et al., 1977), in rat sensory neurons (Hökfelt et al., 1975b), and in instrinsic neurons of the guinea pig intestine (Costa et al., 1977).

Using radioimmunoanalysis (RIA) and immunocytochemistry, we have studied the appearance and development of SLI in various tissues derived from the trunk neural crest in the quail embryo, paying particular attention to the sympathoadrenal system. At the same time, we have established culture conditions which replicate neural crest differentiation as observed in vivo. We show here that the appearance and development of SLI in vitro follow a very similar pattern to that observed in the embryo. In the quail embryo, SLI can be detected in the region of the forming sympathetic ganglia between days 3 and 4 of incubation and in the adrenal gland primordia between days 4 and 5 . Migrating neural crest cells and autonomic ganglioblasts, obtained from 3- and 4-day quail embryos, differentiate in culture into SLI-containing neuron-like cells within 48 and $24 \mathrm{hr}$, respectively. To our knowledge, this is the first description of a neuropeptide produced by neural crest in vitro.

\section{Materials and Methods}

\section{Animals}

Eggs from Japanese quail (Coturnix coturnix japonica), incubated at $38^{\circ} \mathrm{C}$, were used throughout the experiments. The trunks were removed from the embryos from day 2 of incubation until hatching. Different tissues or organs were dissected out and prepared for culture, immunocytochemistry, or RIA.

\section{Isolation of explants}

Presomitic mesenchyme. The unsegmented somitic mesenchyme, i.e., mesoderm posterior to the last pair of somites, was obtained from 2-day embryos (stages 8 and 9 of Zacchei, 1961) by dissociation with $0.2 \%$ pancreatin (Gibco). This presomitic mesenchyme was placed directly in culture without further dissociation. The notochord, isolated at the same time, was added to these cultures.

Sclerotomes. The sclerotomes from 3-day quail embryos (stages 15 and 16 of Zacchei, 1961) were isolated from the neural tube, ectoderm, notochord, and dermo- myotomes after proteolytic treatment of the tissue, as described previously (Cheney and Lash, 1981; Fauquet et al., 1981). About 35 sclerotomes were explanted per culture well.

The sclerotomal portion from 4-day embryos was also enzymatically dissociated and prepared for RIA. (At this stage the sympathetic ganglia and dorsal root ganglia are forming within the sclerotomal mesenchyme.)

Dorsal aorta primordium. The dorsal aorta was surgically removed from the trunk of 4-day quail embryos (stages 18 and 19 of Zacchei, 1961) between the heart and the rectum. The aortas (two to four per well) were dissociated into small pieces using dissecting forceps and were placed directly into the culture dish. Some aortas were prepared for RIA.

Dorsal root and sympathetic ganglia and adrenal glands. Ganglia and glands were isolated surgically from the trunk region of 5-day or older embryos. The lumbosacral sympathetic chains contained 7 to 10 ganglia per chain. Some of these tissues were prepared for RIA.

For cultures, ganglia were rinsed in $\mathrm{Ca}^{++}$-free, $\mathrm{Mg}^{++}$free PBS and trypsinized $(0.25 \%$ trypsin, Gibco) for 20 to $30 \mathrm{~min}$ at $37^{\circ} \mathrm{C}$. Enzymatic action was stopped by adding culture medium. Cells were then mechanically dissociated using a Pasteur pipette, centrifuged, and resuspended in culture medium. Ten sensory or sympathetic ganglia were plated per well.

\section{Culture conditions}

The methods used have been described previously (Fauquet et al., 1981). In brief, multiwell Falcon tissue cultures dishes were used containing approximately 500 $\mu \mathrm{l}$ of medium per well. Cultures were grown at $37^{\circ} \mathrm{C}$ in humidified $\mathrm{CO}_{2}$ : air (5:95). For immunocytochemistry, cells were grown either on plastic coverslips or on collagen (rat tail)-coated glass coverslips.

Two types of culture media were used. For the somitic mesenchyme, sclerotomes, and aortic explants the medium was Dulbecco's Modified Minimal Essential Medium (DMEM; Gibco) supplemented with $15 \%$ heatinactivated fetal calf serum (FCS) and 2\% 9-day chick embryo extract. Culture medium for the sensory and sympathetic ganglia cultures was Eagle's Minimal Essential Medium (MEM) supplemented with $10 \%$ heat-inactivated horse serum, $2 \%$ 9-day chick embryo extract, $0.6 \%$ glucose, $0.29 \mathrm{mg} / \mathrm{ml}$ of glutamine, $0.045 \mathrm{mg} / \mathrm{ml}$ of $\mathrm{KCl}, 0.02 \mathrm{mg} / \mathrm{ml}$ of choline chloride, 50 units $/ \mathrm{ml}$ of penicillin, and $50 \mu \mathrm{g} / \mathrm{ml}$ of streptomycin sulfate. 7S NGF (gift of Dr. M. Weber) was added to the medium at a final concentration of $50 \mathrm{ng} / \mathrm{ml}$.

\section{Antibody production}

One-half milligram of somatostatin 1-14 (Sigma) was coupled to $2 \mathrm{mg}$ of BSA using para-benzoquinone (Ternynck and Avrameas, 1976). Rabbits were immunized against one-eighth of the BSA-somatostatin complex mixed 1:1 with complete Freund's adjuvant (Gibco). Injections were done at 4- to 6 -week intervals, and serum was obtained 7 and 14 days after each injection. Antisomatostatin antibodies were obtained after the second injection. Antibody 2-189 was used at a dilution of 1:1,000 for immunocytochemistry and 1:20,000 for RIA. Al- 
though this antibody also recognizes somatostatin 1-28 in RIA, it is more sensitive to somatostatin 1-14; whereas $12 \mathrm{pg}$ of the unlabeled molecule are required to displace $50 \%$ of the bound radioactive tracer, 10 times this amount of the 1-28 molecule is needed to cause the same displacement.

The results obtained with our antibody (2-189) were compared to results obtained with two other antibodies. Antisomatostatin from Institut Pasteur Productions was used for RIA at a dilution of 1:20,000. The second antibody, a gift from Dr. P. Brazeau, was used for RIA diluted $1: 2,000$ and for immunocytochemistry at 1:1,000.

\section{Immunocytochemistry}

In vivo. Trunks were removed from embryos after 3 days of incubation until hatching. Immediately after removal, the tissues were fixed for $20 \mathrm{~min}$ at $4^{\circ} \mathrm{C}$ in a solution of $0.4 \%$ para-benzoquinone in $0.01 \mathrm{M}$ PBS $(\mathrm{pH}$ 7.4). Specimens were then thoroughly rinsed in PBS containing $7 \%$ sucrose and $0.01 \%$ sodium azide and were left overnight at $4^{\circ} \mathrm{C}$ in this buffer. They were subsequently frozen for cryostat sectioning. Sections ( 7 to 10 $\mu \mathrm{m})$ were picked up on gelatin-coated slides. Indirect immunofluorescence staining was done (Coons et al., 1955) using antisomatostatin serum. Serial sections were incubated for $16 \mathrm{hr}$. Fluorescein isothiocyanate (FITC)labeled goat-anti-rabbit antibody (Capell) was then applied at a dilution of 1:100 for $1 \mathrm{hr}$ at room temperature. After washing in PBS, the sections were mounted in PBS-glycerol (1:3).

Sympathetic ganglion sections were photographed and then treated with a modification of the acridine orange method (J. Fontaine-Pérus and M. Chanconie, manuscript in preparation). This permitted us to visualize and quantify the number of cells in each section. Photographs were taken, and the proportion of SLI-containing cells to the number of cells in the section was determined.

In vitro. Procedures utilized for culture immunocytochemistry were modified from those described by Hartman (1973). Cultures were fixed in $4 \%$ paraformaldehyde for 90 min followed by several rinses with PBS (pH 7.4). A 10 -min rinse in $0.25 \%$ Triton to permeabilize the cells was followed by a 30-min rinse in 1:30 goat serum to minimize background staining. Cultures were incubated with rabbit somatostatin antiserum at room temperature for $30 \mathrm{~min}$ and overnight at $4^{\circ} \mathrm{C}$. FITC-labeled goat-antirabbit fluorescent antibody (Nordic) was added at a dilution of 1:50 for $30 \mathrm{~min}$ at room temperature.

Prior to use, somatostatin antisera (1:100 dilution) were absorbed with PBS, $0.5 \%$ BSA for $24 \mathrm{hr}$ at $4^{\circ} \mathrm{C}$ followed by centrifugation at $10,000 \times g$ for $60 \mathrm{~min}$ to eliminate any anti-BSA antibodies. Diluted serum plus $1 \mu \mathrm{g} / \mathrm{ml}$ of synthetic somatostatin and pre-immunization serum were used as controls.

\section{Radioimmunoanalysis}

Sample preparation for RIA. Tissues or cultures were rinsed in PBS, extracted in $200 \mu \mathrm{l}$ of $2 \mathrm{M}$ acetic acid, boiled for $10 \mathrm{~min}$, and centrifuged at $3000 \times \mathrm{g}$ for $5 \mathrm{~min}$. The supernatant was then freeze-dried. Prior to lyophilization, an aliquot was removed for protein analysis and frozen at $-20^{\circ} \mathrm{C}$. The samples for RIA were kept at $-70^{\circ} \mathrm{C}$ until required, when they were dissolved in 0.05 $\mathrm{M}$ potassium phosphate buffer $(\mathrm{pH} 7.4)$ containing $0.5 \%$ $\mathrm{BSA}$ and $0.01 \% \mathrm{Na}$ azide and were centrifuged at 10,000 $\times g$ for $15 \mathrm{~min}$ to eliminate any precipitate obtained after lyophilization. Protein was measured by the method of Lowry et al. (1951).

Iodination of somatostatin was performed using chloramine T (see Garvey et al., 1977). Thirty micrograms of Tyr-somatostatin (Sigma) were reacted with $0.5 \mathrm{mCi}$ of ${ }^{125} \mathrm{I}$ (Amersham) in the presence of $20 \mu \mathrm{g}$ of chloramine $\mathrm{T}$ (Sigma). The reaction was stopped after $15 \mathrm{sec}$ by addition of $20 \mu \mathrm{g}$ of sodium bisulfite. Immunoreactive $\left[{ }^{125} \mathrm{I}\right]$-Tyr-somatostatin was separated from other components on a G-25 Sephadex column.

For RIA, $100 \mu \mathrm{l}$ of the antibody dilution were mixed in a test tube with $100 \mu \mathrm{l}$ of the sample to be measured. Standard curves were derived from $9000 \mathrm{pg} / \mathrm{ml}$ to $2.5 \mathrm{pg} /$ $\mathrm{ml}$ of synthetic somatostatin (Sigma). After an initial incubation of antibody and sample for $5 \mathrm{hr}$ at $4^{\circ} \mathrm{C}, 100$ $\mu \mathrm{l}$ of the tracer dilution $(6,000$ to $10,000 \mathrm{cpm})$ were added. Free and bound somatostatin were separated by precipitation of the latter with $0.5 \mathrm{ml}$ of propanol followed by centrifugation at $2000 \times g$ for $20 \mathrm{~min}$. The supernatant was discarded, and the radioactivity in the precipitate was measured in a Beckman 4000 Gamma Counter.

\section{Results}

Characterization of SLI. Various lines of evidence lead us to believe that the SLI described here is, in fact, elicited by somatostatin or a very similar peptide:

1. SLI was recognizable in the pancreas (both by RIA and immunocytochemistry), which is known to contain somatostatin (Arimura et al., 1975; Alumets et al., 1977).

2. SLI could be blocked by pre-incubation of the antibody with synthetic somatostatin $(1 \mu \mathrm{g} / 10 \mu \mathrm{l}$ of serum).

3. The same pattern of fluorescence as seen with our antibody was obtained both in vivo and in vitro using another somatostatin antibody (gift from Dr. Brazeau).

4. We obtained virtually identical standard curves for synthetic somatostatin using three different somatostatin antibodies: our own (2-189), antibody obtained from the Institut Pasteur Productions, and antibody obtained from Dr. P. Brazeau. The same measurements were obtained from tissue and culture extracts using each of the three antibodies.

5. Serial dilutions of extracts from sclerotomal cultures, sympathetic ganglia, or adrenal glands followed the same slope as the successive dilutions of synthetic somatostatin in the standard curve.

Development of SLI in sympathelic ganglia. The first immunoreactive sites in the sympathetic ganglia were observed in 4-day embryos and consisted of cell bodies and fibers uniformly distributed in each ganglion irrespective of the level (Fig. 1a). At this early stage of development, the cells were weakly fluorescent, and the immunofluorescence encompassed the entire ganglion. From day 5 to day 8 of incubation, immunoreactive fibers and neurons became numerous and highly fluorescent. However, beyond this stage we observed a considerable decrease in the density of fluorescent structures. At as early as day 9 of incubation, SLI was restricted to a few highly fluorescent nerve cell bodies and their processes, 

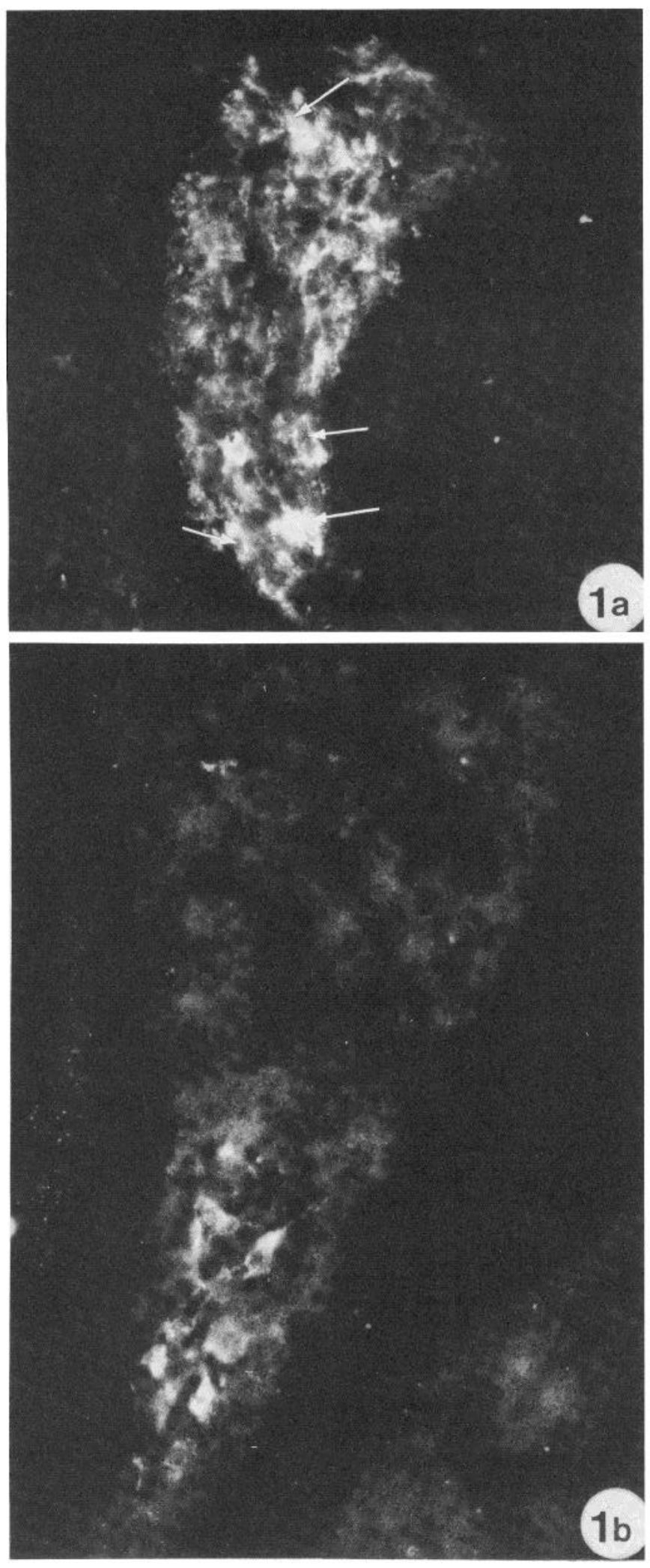

Figure 1. Transverse section of the trunk sympathetic ganglion of a 6-day quail embryo $(a)$. The immunoreactivity observed over the entire ganglion consists of nerve fibers and processes and nerve cell bodies (arrows). In the 13-day quail embryo $(b)$, SLI was restricted to a few nerve cell bodies and their processes exclusively located to the ventral area of the ganglion. Magnification $\times 180$. located in the ventral area of each ganglion (Fig. 1b). This distribution was maintained until hatching.

As assessed by RIA and immunocytochemistry, no SLI was found before or at 3 days of incubation in neural crest cells or in the tissues that abut their routes of migration, i.e., neural tube, sclerotomal mesenchyme, dermomyotome, ectoderm, or notochord.

RIA confirmed the presence of SLI in the 4-day embryo. At this age, SLI was found in extracts of the sclerotomal portion of the embryo, which includes the site of development of the sympathetic ganglia. After day 6 of incubation, the lumbosacral sympathetic chain can be dissected free of contaminating tissues. The development of SLI in these sympathetic chain ganglia is represented in Figure 2, which shows the amount of SLI per microgram of protein. If the amount of SLI is expressed as SLI per ganglion instead of per unit of protein, we observe a significant reduction $(p<0.01)$ of SLI from ages 6 and $7(2.06 \pm 0.3 \mathrm{pg} /$ ganglion $\pm \mathrm{SE})$ to ages 10 to $13(0.85 \pm 0.087)$.

In Table I we show that the proportion of SLI-containing cells present in the sympathetic ganglion decreases as the embryo ages. It must be emphasized that the value of $7 \%$ for the SLI-containing cells in sympathetic ganglia of the 6-day embryo is in reality an underestimate, since only the most strongly immunoreactive cells were taken into account (whereas the entire ganglion appears to exhibit a weak fluorescence at this age). In addition, intense fluorescence in the 6-day ganglion is often localized to small clusters of cells in which it can

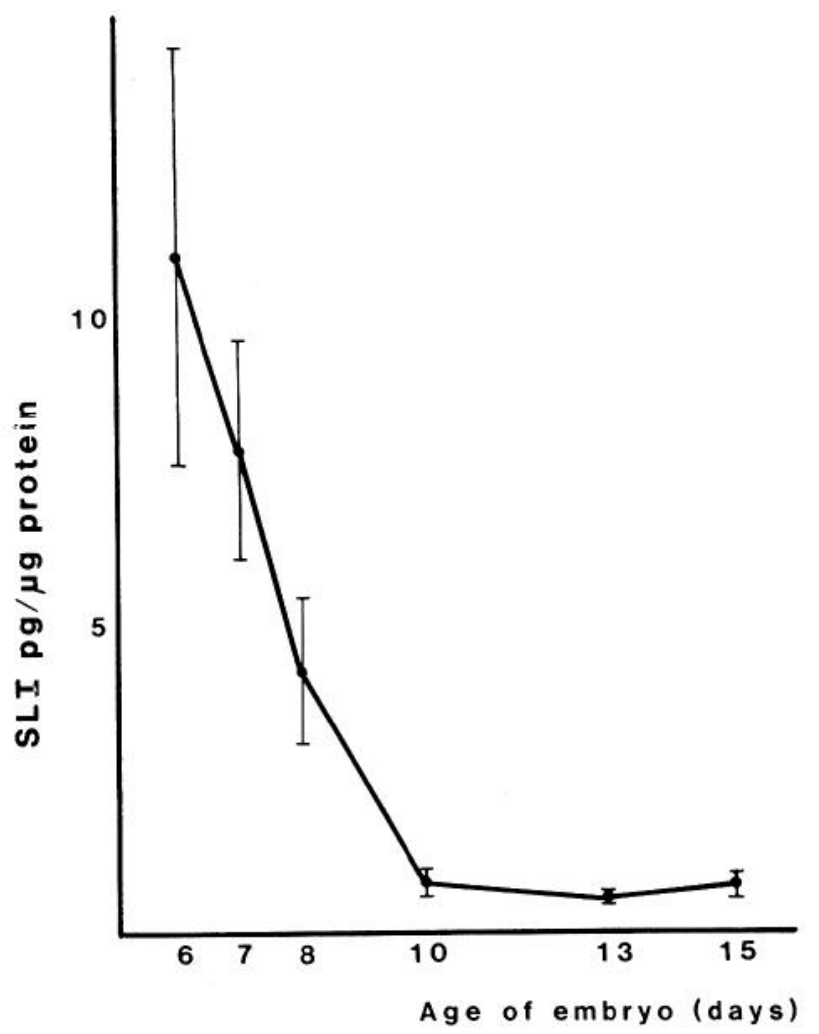

Figure 2. Development of SLI in the sympathetic ganglionic chain of quail embryos. Results represent the mean of at least four RIA on two to six sympathetic chains per assay and are expressed in terms of protein content. Bars represent SEM. 
TABLE I

SLI-containing cells in sympathetic ganglia

SLI-containing cells, quantified in tissue sections by immunofluorescence, were compared with the total number of cells observed by counting nuclei in the same sections after treatment with acridine orange. Results are expressed as mean \pm SEM. Significance was determined by the Student's $t$ test. Each value corresponds to at least six different sections of sympathetic ganglia from three embryos.

\begin{tabular}{cccc}
\hline $\begin{array}{c}\text { Embryonic } \\
\text { Age }\end{array}$ & $\begin{array}{c}\text { No. of Cells } \\
\text { Containing SLI }\end{array}$ & $\begin{array}{c}\text { Total No. } \\
\text { of Cells }\end{array}$ & Percentage \\
\hline days & & & \\
6 & $23.1 \pm 3$ & $342 \pm 37$ & $\begin{array}{c}6.89 \pm 0.6 \\
p<0.001\end{array}$ \\
& & & $2.64 \pm 0.6$ \\
& $13 \pm 2.7$ & $515 \pm 35$ & $p<0.01$ \\
& & & $0.43 \pm 0.05$ \\
\hline
\end{tabular}

be difficult to determine whether SLI is displayed by one cell or several. In such cases, SLI was assigned to a single cell only.

SLI could also be detected by immunocytochemistry in cultures of sympathetic ganglia 7 days after plating. In the small ganglion-like structures formed in these cultures, a few strongly SLI-positive cells were found (Fig. 3). Other less fluorescent cells were sometimes present, although in no instance were all cells forming the ganglion positive. SLI-containing cells displayed fluorescence over the entire cell body (except for the nuclei) and often over the neurites and in enlargements or varicose-like structures as well. However, only rarely did the SLI extend in the neurite network from one ganglion to the next.

Development of SLI in the adrenal gland and aortic plexus. SLI-containing cells were observed at the level of the adrenal gland in 5-day embryos, i.e., when the primordia of the gland first appear (Fig. 4a). However, even earlier, at 4.5 days, some SLI cells were seen around the area where the adrenal would later form. Although at first weakly immunoreactive, medullary cells became intensely fluorescent as the embryo aged, and the number of reactive cells increased considerably until hatching (Fig. $4 b$ ). Most, if not all, of the chromaffin cells in the adrenal medulla appeared positive in the older embryos. However, immunoreactive cells displayed fluorescence that ranged from intense to weak. No structural difference could be correlated to the difference in fluorescence intensity.

In the adrenal gland, SLI was detectable by RIA at 5 days of age and increased in amount during the subsequent days (Fig. 5). This increase is evident both by plotting the amount of SLI with respect to the amount of protein (as in the figure) or the amount of SLI per gland. For example, the amount of SLI per gland rose from $2 \mathrm{pg} / \mathrm{gland}$ at 5 days of incubation to about $50 \mathrm{pg} /$ gland at 8 days of incubation, with $1000 \mathrm{pg} /$ gland present at 13 days of incubation.

The development of SLI cells in the aortic plexus paralleled their development in the adrenal gland. Cells displaying SLI first appeared as soon as the plexus started to form, between days 3 and 4 of incubation, and maintained their immunofluorescence until hatching.
The aorta can be dissected out after 4 days of incubation; no SLI was found by RIA at this age. However, SLI was already present in aortas taken at 5 days of incubation.

Development of SLI in the dorsal root ganglia. In the dorsal root ganglia, no SLI cells were found until day 13 of incubation. At this stage, very few immunofluorescent nerve cell bodies were detected, and these were preferentially dispersed among the small-sized neuron population (Fig. 6), which has been shown to display substance P immunoreactivity (Fontaine-Pérus et al., 1982). Their fluorescence, although weak, appeared granular and clearly concentrated in the perinuclear space. No SLI detectable by RIA was found in the sensory ganglia up to 12 days of embryonic age (the latest stage examined). Beyond this age, it is virtually impossible to obtain dorsal root ganglia that are free of contamination from the sympathetic ganglia, a part of which becomes attached to the sensory ganglia. Since the sympathetic chain contains SLI, no significant conclusion could be drawn from RIA.

We were unable to detect SLI by RIA or by immunocytochemistry in cultures of 7- to 9-day quail embryo sensory ganglia 2,7 , or 14 days after plating.

Development of SLI in sclerotome cultures. When the sclerotomal moiety of 3-day embryos (which contains the migrating neural crest cells) was placed in culture, SLI could be detected by RIA $48 \mathrm{hr}$ later. The quantity of SLI in these cultures increased during the following days, reaching a constant level between 4 and 6 days of culture (Fig. $7 A$ ). The amount of protein in these cultures also increased with age (Fig. $7 B$ ). However, the amount of protein is not an appropriate index of SLI development, since it reflects the development both of non-neuronal and neuronal cell types. This discrepancy between protein content and SLI development could be seen in 6day cultures, where the amount of protein continued to increase, whereas SLI content reached a plateau.

To show that the RIA-detectable SLI did not originate from the mesenchymal cells, we cultured 2-day preso-

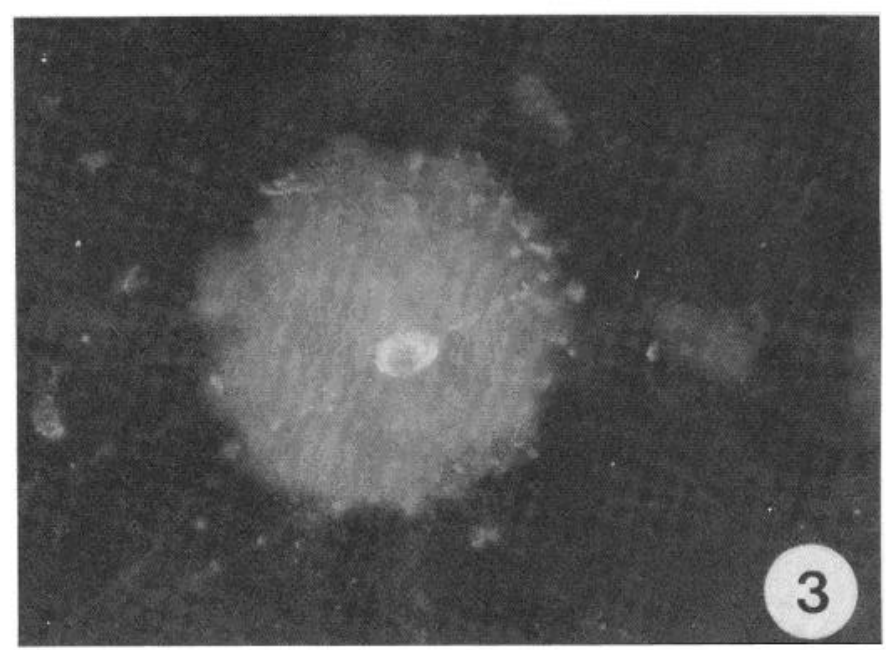

Figure 3. SLI-containing cell in 9-day quail embryo sympathetic ganglion cultured for 7 days. The soma and neurites of the cell are immunoreactive. Magnification $\times 350$. 

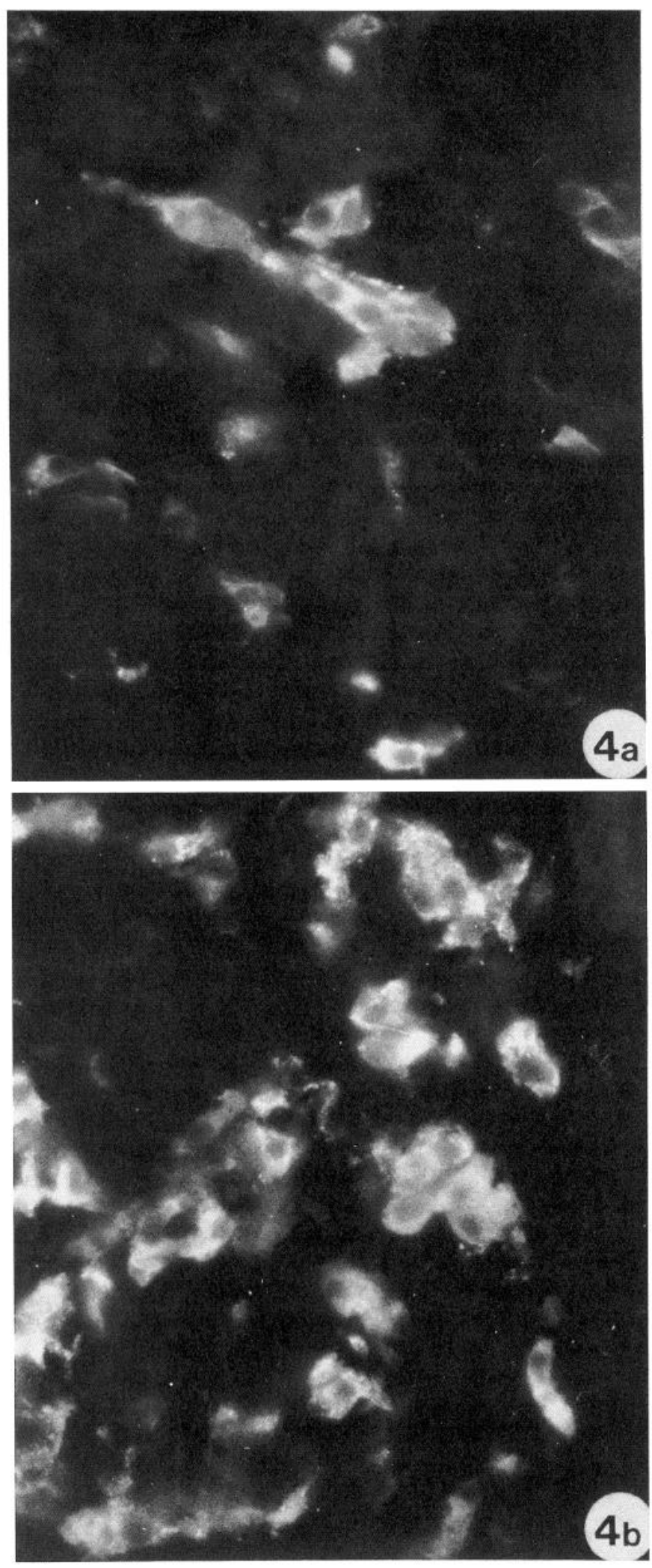

Figure 4. Adrenal gland of 9-day quail embryo (a). SLIcontaining cells are observed in the medullary component of the gland. $b$, In the 14-day embryo, the intensity of the immunofluorescence and the number of immunoreactive cells have increased. Magnification $\times 700$.

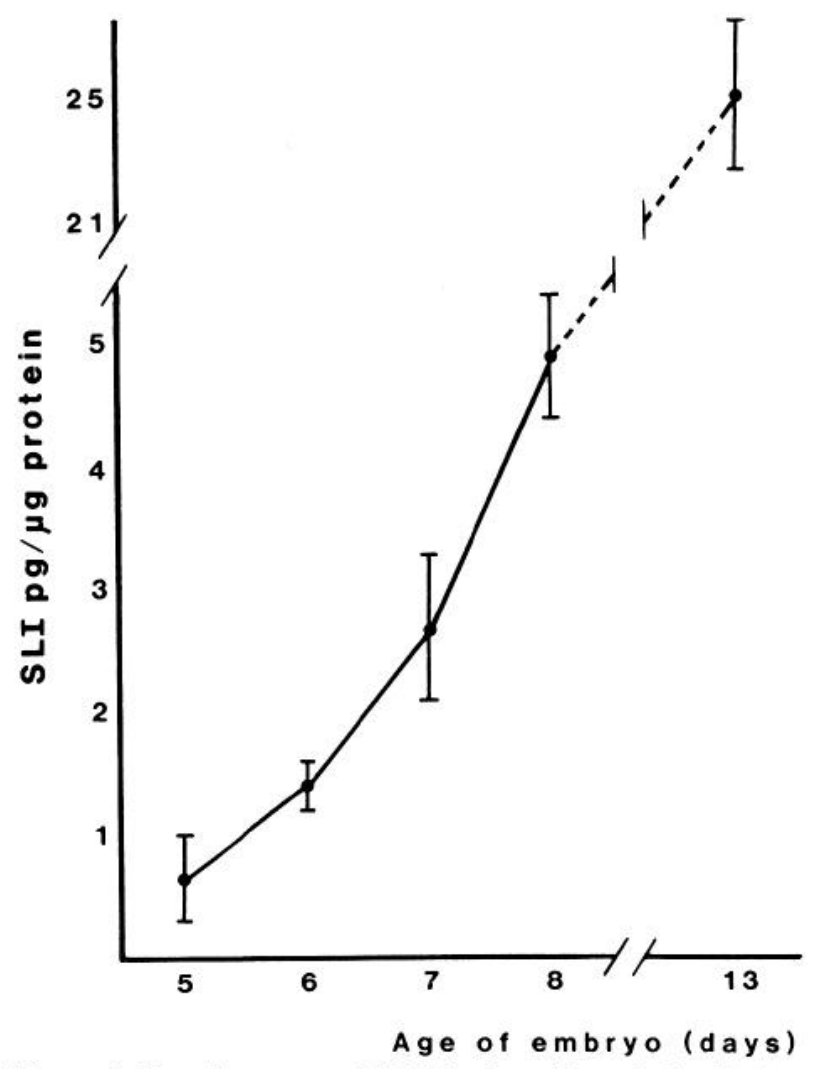

Figure 5. Development of SLI in the adrenal gland of quail embryos. Results represent the mean of at least three RIA on 2 to 14 adrenal glands per assay and are expressed in terms of the gland's protein content. Bars represent SEM.

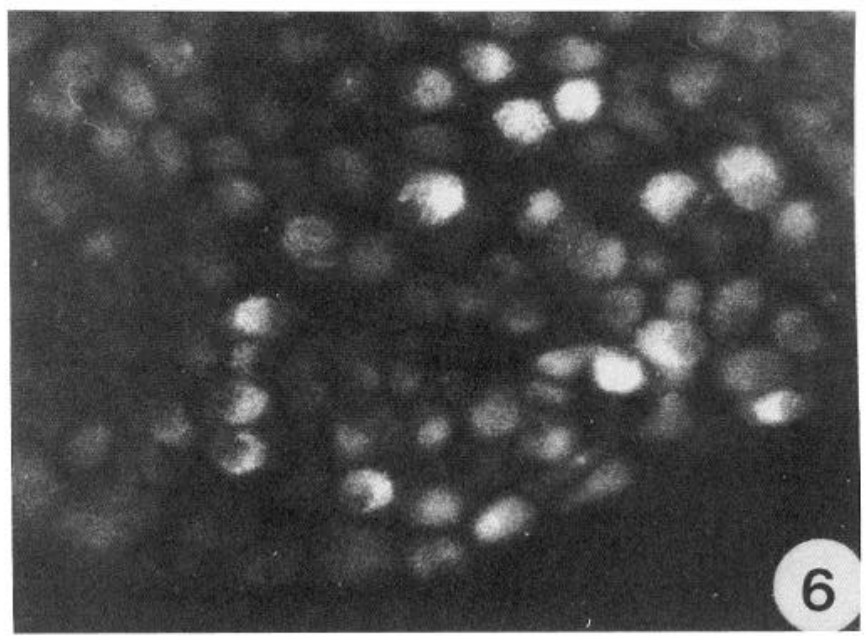

Figure 6. Transverse section of a sensory ganglion from a 13-day quail embryo. SLI is present in a few weakly immunostained nerve cell bodies corresponding to the mediodorsal area of the spinal ganglion. Magnification $\times 200$.

mitic mesenchyme. In vivo this mesenchyme gives rise to the sclerotome and the dermomyotome. In the 2-day embryo, neural crest cells at the level of the unsegmented somites have not yet migrated, so that no presumptive neuronal cells are present when the presomitic mesenchyme is cultured at this age. No SLI could be detected by RIA in these cultures, even after 7 days. 


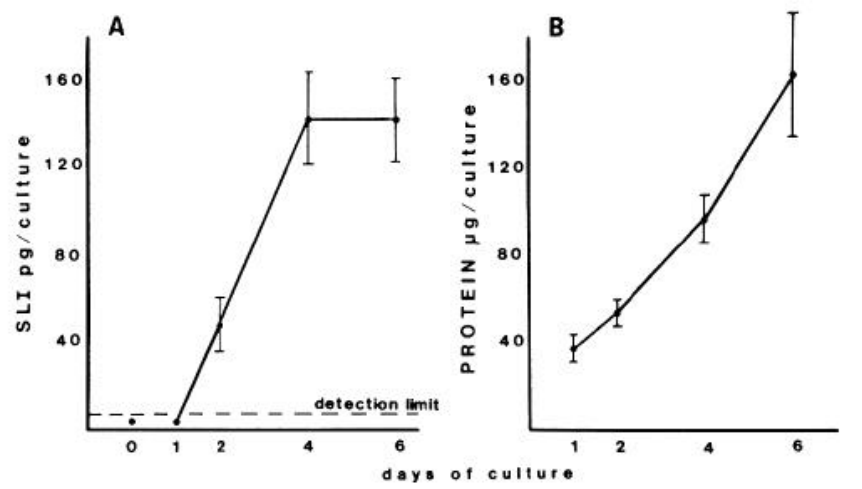

Figure 7. Development of $(A) \mathrm{SLI}$ and $(B)$ protein content in cultures of sclerotomes. Thirty-five sclerotomes were grown per culture, and two cultures were pooled for each assay. The values represent the mean \pm SEM of at least six RIA and protein assays. In attempts to detect SLI before culture, trunk extracts containing up to 250 sclerotomes were grouped.

To identify the cell types that contained the SLI detected by RIA, we carried out immunocytochemistry on 4- to 6-day-old cultures, in which the amount of SLI had reached a plateau. We found that many neuron-like cells (such as those described by Fauquet et al., 1981) were positive for SLI (Fig. 8, $A$ to $C$ ). Immunoreactivity was shown by isolated cells, cells forming small ganglionlike aggregates, and cells associated in large plexus-like structures. These positive cells resembled the SLI-containing cells present in the sympathetic ganglion cultures. The degree of fluorescence, as in vivo, varied from intensely fluorescent to weak.

Development of SLI in aortic explants. At 4 days of incubation, some of the cells of the neural crest have migrated to the area around the developing aorta. Here they differentiate in situ or emigrate to colonize other areas, forming derivatives such as the adrenal gland, the aortic plexus, and the sympathetic ganglia (Enemar et al., 1965; see also Romanoff, 1960; Le Douarin, 1982). To see whether these sympathoadrenal precursors also differentiate in vitro into SLI-containing neurons, the dorsal aorta of 4-day embryos was dissected and placed in culture. After 1 day, some neuron-like cells (both isolated and in small groups) had developed, particularly at the periphery of the aortic explant. After 2 days in culture, more of these cells could be seen, some of them grouping together into ganglion-like structures.

No SLI was detectable by RIA in freshly dissected aortas from 4-day embryos, as previously described. The first positive reaction was detected in aortic explant cultures after $24 \mathrm{hr}$ (Fig. 9A). The amount of SLI increased during the next few days. In contrast to the sclerotome cultures, the amount of protein in these cultures did not increase over time (Fig. 9B).

By immunocytochemistry, many SLI-positive cells could be observed in plexus-like structures contained within the aortic explant, while other SLI-containing cells were found alone or associated with small ganglia around the explant. The morphology of these neurons was very similar to that of cells developing in sclerotome and sympathetic ganglion cultures (Fig. 10).


Figure 8. SLI-containing cells in sclerotome cultures kept 4 to 6 days. These neuron-like cells present diverse morphologies and are found $(a)$ isolated, $(b)$ grouped in small ganglion-like structures, or (c) forming plexuses with numerous immunoreactive fibers and where the cell bodies (arrow) are barely discernible. Magnification $\times 350$.

\section{Discussion}

The studies described here show that the distribution of SLI-containing cells in quail embryos is similar to that of mammals, i.e., SLI is present in the adrenal gland (Lundberg et al., 1979), in the sympathetic ganglia (Hök- 


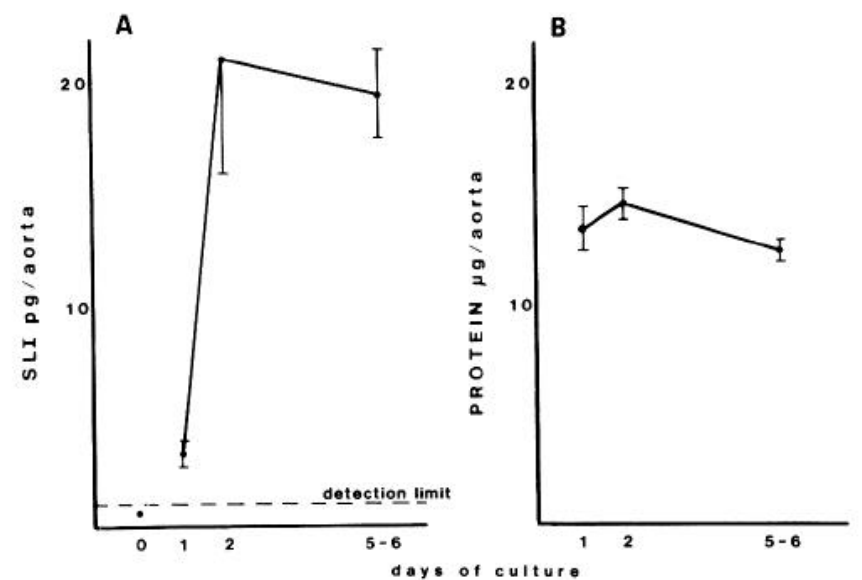

Figure 9. Development of $(A)$ SLI and $(B)$ protein content in cultures of aortic explants. Two to four aortas were grown per culture, and two cultures were pooled for each assay. The values represent the mean \pm SEM of at least four RIA and protein assays. In attempts to detect SLI before culture, up to 10 aortic explants were grouped for RIA.

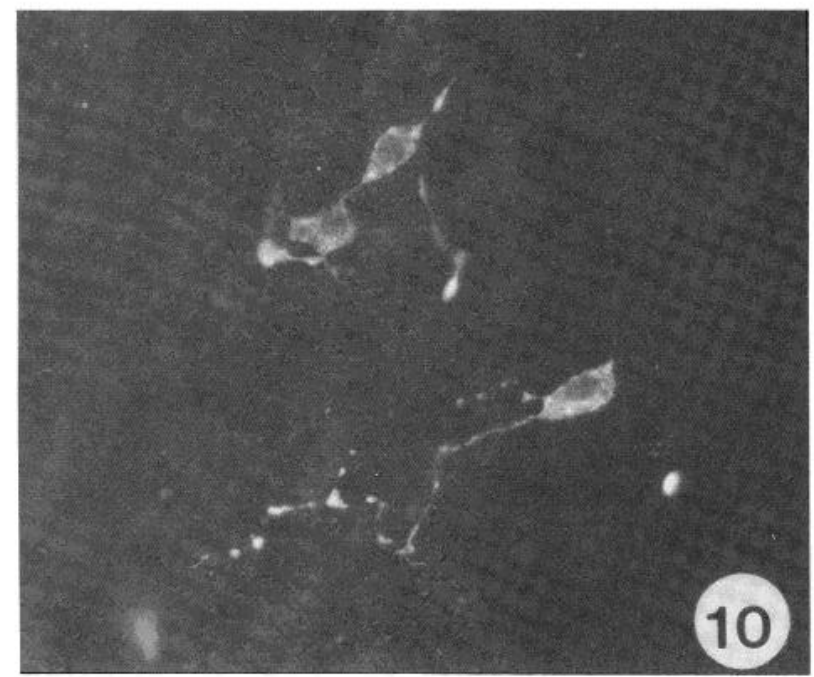

Figure 10. SLI-containing cells in aortic explant cultured for 6 days. Magnification $\times 350$.

felt et al., 1977), and in the sensory ganglia (Hökfelt et al., 1975b).

Time of appearance of SLI. The appearance of SLI is an early event in the differentiation of neural crest into either sympathetic ganglia or adrenomedullary cells. In the avian embryo, at 3 days of incubation, the trunk neural crest cells are migrating between the sclerotomeneural tube and the sclerotome-dermomyotome boundaries and in the narrow intersomitic space (Le Douarin and Teillet, 1974; Thiery et al., 1982; Le Douarin et al., 1983). SLI is detected soon after the cells aggregate to form the primary sympathetic chain, which occurs at 3.5 days in the chick embryo (Kuntz, 1910; Yntema and Hammond, 1947; Enemar et al., 1965) or when they colonize the primordium of the adrenal gland, between days 4 and 5 of incubation (Enemar et al., 1965). Similar events have been described for other peptides, such as substance $\mathrm{P}$ in the sensory ganglia (Fontaine-Pérus et al., 1982) and methionine-enkephalin in the ganglia of Remak (Epstein and Dahl, 1982), which are detected soon after the ganglia are formed. In contrast, SLI does not appear in the dorsal root ganglia until long after they are formed.

In vitro, SLI also appears soon after the neural crest cells have differentiated into neuron-like cells. Fauquet et al. (1981) have shown that after the sclerotomes have been in culture for $24 \mathrm{hr}$, some crest cells extend processes, and after $48 \mathrm{hr}$, when SLI is first detected by RIA, cells appear with highly refractile spherical cell bodies and processes. Some of them aggregate to form ganglionlike structures or an intricate meshwork.

When aortic explants containing presumptive autonomic ganglioblasts were cultured, SLI appeared after 24 $\mathrm{hr}$. However, it should be underlined that these cells had continued their development in the embryo for an extra $24 \mathrm{hr}$ and that they were placed in culture as a virtually undissociated explant.

The timing of SLI appearance in vitro corresponded to that in the embryo except for a small delay in our sclerotome cultures. SLI appeared in vitro at what corresponds to day 5 of incubation in the embryo, the age when it appears in the aortic plexus and adrenal gland, and about $24 \mathrm{hr}$ after it appears in the sympathetic ganglia.

Development of SLI. The development of SLI in the sympathetic ganglia is a curious phenomenon. Although in the early stages of development the immunofluorescence extended over the entire ganglion, soon afterward (around day 9) only a few, ventrally localized positive cells remained. However, the amount of SLI per ganglion decreased only slightly during embryonic life. Since in younger embryos a higher proportion of cells in the sympathetic chain was SLI-positive, it must be assumed, therefore, that SLI-containing cells give rise to cells that lose their SLI or that the few SLI-negative cells divide to form most of the adult ganglion, while the SLIcontaining cells remain few in number. An alternate hypothesis is that naturally occurring cell death decreases selectively the proportion of SLI-containing cells. Rothman and her colleagues (1978) have shown that some cells become postmitotic very early in the formation of the sympathetic ganglia, while others continue to divide. It would be interesting to correlate the acquisition of SLI with the cells' mitotic activity.

The development of SLI in the adrenal gland contrasted with that in the sympathetic ganglia. Whereas in the latter the amount of SLI remained stable, in the adrenal gland it increased as the embryo aged. It is interesting to note that in the adrenal medulla most, if not all, of the chromaffin cells seemed to contain SLI fluorescence at every stage in the embryo.

In our cultures, the development of SLI-containing cells was similar to that of the sympathetic ganglion in vivo, i.e., the amount of SLI reached a plateau a few days after its initial appearance. This finding is in agreement with previous work by our group showing that this type of culture favors the differentiation of sympathetic neurons (Fauquet et al., 1981).

Comparison of SLI and adrenergic development. An interesting fact that must be underlined is that the development of SLI in vivo and in vitro follows a pattern very similar to that of adrenergic cells of the sympathoadrenal system. In both cases, the appearance of SLI 
seems to correspond to the time of differentiation of neural crest cells into sympathetic or adrenal cells.

In vivo, adrenergic properties, defined by catecholamine fluorescence, appear at about 3.5 days in the primary (and soon after in the secondary) sympathetic ganglia of the chick embryo (Enemar et al., 1965; Kirby and Gilmore, 1976) and at 4 to 5 days in the adrenal gland (Enemar et al., 1965). The catecholamine fluorescence intensity of the secondary sympathetic ganglia diminishes in the 9- to 10-day chick embryo, while in the adrenal medullary cells, on the contrary, the intensity continues to increase (Enemar et al., 1965). This is similar to what we have observed for SLI. In some mammals, somatostatin immunofluorescence and adrenergic properties have been found to coexist in the same cells of the adrenal medulla (Lundberg et al., 1979) and in some noradrenergic sympathetic neurons (Hökfelt et al., 1977). However, somatostatin is not the only peptide in sympathetic neurons; Lundberg and his colleagues (1982) showed avian pancreatic polypeptide also to be present in sympathetic noradrenergic neurons (although in a different population from those containing somatostatin) and vasoactive intestinal peptide (VIP) to be present in a subpopulation of sympathetic neurons which are thought to be cholinergic.

As for development in vitro, cells differentiating in sclerotome cultures have been shown to possess many neuronal properties. They can be stained by silver impregnation, and they contain catecholamines, acetylcho linesterase (Fauquet et al., 1981), tyrosine hydroxylase, tetanus toxin-binding sites, and neurofilaments (M. Fauquet and C. Ziller, personal communication).

Most neuronal cells in this type of culture are clearly adrenergic sympathetic neurons (Smith et al., 1981). Our group has shown that catecholamines can be synthesized by sclerotomal cultures after $24 \mathrm{hr}$ and that the synthesizing capacity increases after 7 days in culture (Fauquet et al., 1981). Most if not all of the neuronal cells in these cultures are fluorescent after glyoxylic acid treatment, and numerous dense-core vesicles, characteristic of adrenergic neurons, have been described in these cells.

In view of the similarities in the development of catecholamines and SLI in differentiating neurons, we have started to study the possibility that both characteristics are expressed by the same cells. Preliminary results indicate that SLI-positive cells also contain tyrosine hydroxylase, the rate-limiting enzyme for catecholamine synthesis, and that they are fluorescent after glyoxylic acid treatment, a test for the presence of catecholamines.

Somatostatin is known to be an inhibitory peptide in the CNS, pituitary, pancreas, and digestive tube (for references see Arimura et al., 1975; Renaud et al., 1975). Its function in the peripheral nervous system is not known, although there is some evidence that it inhibits cholinergic-mediated catecholamine release in the adrenal medulla (Mizobe et al., 1979; Role et al., 1981) and that it might modulate tyrosine hydroxylase activity in sympathetic ganglia (Kessler et al., 1983). Its early appearance in association with adrenergic tissues suggests a tight interrelationship between somatostatin and catecholamines.

The cultures described in this article represent conditions in which neural crest precursors differentiate into somatostatin-containing neurons. We believe that these cultures may provide a system to study the influence of different factors on the differentiation of peptidergic neurons, in the same way that they have been used to study the differentiation of neural crest cells into catecholamine- or acetylcholine-synthesizing neurons.

Note added in proof. Recently, two articles presenting results similar to those described here have been published by Maxwell et al. (1984; Dev. Biol. 101: 357-366).

\section{References}

Alumets, J., F. Sundler, and R. Hakanson (1977) Distribution, ontogeny and ultrastructure of somatostatin. Immunoreactive cells in the pancreas and gut. Cell Tissue Res. 185: 465479.

Arimura, A., H. Sato, A. Dupont, N. Nishi, and A. V. Schally (1975) Somatostatin: Abundance of immunoreaclive hormone in rat stomach and pancreas. Science 189: 1007-1009.

Ayer-Le Lièvre, C., and J. Fontaine-Pérus (1982) The neural crest: Its relation with APUD and paraneuron concepts. Arch. Histol. Jpn. 45: 409-427.

Brazeau, P., W. Vale, R. Burgus, N. Ling, M. Butcher, J. Rivier, and R. Guillemin (1973) Hypothalamic polypeptide that inhibits the secretion of immunoreactive pituitary growth hormone. Science 179: 77-79.

Cheney, C. M., and J. W. Lash (1981) Diversification within embryonic chick somites: Differential response to notochord. Dev. Biol. 81: 288-298.

Cohen, A. M. (1972) Factors directing the expression of sympathetic nerve traits in cells of neural crest origin. J. Exp. Zool. 179: 167-182.

Coons, A. J., E. Leduc, and J. M. Connolly (1955) Studies on antibody production. I. Method for the histochemical demonstration of specific antibody and its application to the study of the hyperimmune rabbit. J. Exp. Med. 102: 49-59.

Costa, M., Y. Pastel, J. B. Furness, and A. Arimura (1977) Evidence that some intrinsic neurons of the intestine contain somatostatin. Neurosci. Lett. 6: 215-222.

Enemar, A., B. Falck, and R. Hakanson (1965) Observations on the appearance of norepinephrine in the sympathetic nervous system of the chick embryo. Dev. Biol. 11: 268-283.

Epstein, M., and J. L. Dahl (1982) Development of enkephalin in the rectum and ganglion of Remak of the chick. Peptides 3: $77-82$.

Fauquet, M., J. Smith, C. Ziller, and N. M. Le Douarin (1981) Differentiation of autonomic neuron precursors in vitro: Cholinergic and adrenergic traits in cultured neural crest cells. J. Neurosci. 1: 478-492.

Fontaine-Pérus, J., C. Le Lièvre, and M. P. Dubois (1980) Do neural crest cells in the pancreas differentiate into somatostatin-containing cells? Cell Tissue Res. 213: 293-299.

Fontaine-Pérus, J., M. Chanconie, and N. M. Le Douarin (1982) Differentiation of peptidergic neurons in quail-chick chimaeric embryos. Cell Diff. 11: 183-193.

Garvey, J. S., N. E. Cremer, and D. H. Sussdorf (1977) Methods in Immunology, Ed. 3, W. A. Benjamin, Inc., Menlo Park, CA.

Hartman, B. K. (1973) Immunofluorescence of dopamine- $\beta$ hydroxylase. Application of improved methodology to the localization of the peripheral and central noradrenergic nervous system. J. Histochem. Cytochem. 21: 312-332.

Hökfelt, T., S. Efendic, C. Hellerström, O. Johansson, R. Luft, and A. Arimura (1975a) Cellular localization of somatostatin in endocrine-like cells and neurons of the rat with special references to the A1-cells of the pancreatic islets and to the hypothalamus. Acta Endocrinol (Kbh.) 80 (Suppl. 200): 141. 
Hökfelt, T., R. Elde, O. Johansson, R. Luft, and A. Arimura (1975b) Immunohistochemical evidence for the presence of somatostatin, a powerful inhibitory peptide, in some primary sensory neurons. Neurosci. I ett. 1: 231-235.

Hökfelt, T., L. G. Elfvin, R. Elde, M. Schultzberg, M. Goldstein, and R. Luft (1977) Occurrence of somatostatin-like immunoreactivity in some peripheral sympathetic noradrenergic neurons. Proc. Natl. Acad. Sci. U. S. A. 74: 3587-3591.

Hökfelt, T., O. Johansson, A. Ljungdahl, J. W. Lundberg, and M. Schultzberg (1980) Peptidergic neurones. Nature 284: $515-521$

Hörstadius, S. (1950). The Neural Crest: Its Properties and Derivatives in the Light of Experimental Research, Oxford University Press, London.

Kessler, J. A., J. E. Adler, and I. B. Black (1983) Substance P and somatostatin regulate sympathetic noradrenergic function. Science 221: 1059-1061.

Kirby, M. L., and S. A. Gilmore (1976) A correlative histofluorescence and light microscopic study of the formation of the sympathetic trunks in chick embryos. Anat. Rec. 186: 437450.

Kuntz, A. (1910) The development of the sympathetic nervous system in birds. J. Comp. Neurol. 20: 211-258.

Le Douarin, N. M. (1980) The ontogeny of the neural crest in avian embryo chimaeras. Nature 286: 663-669.

Le Douarin, N. M. (1982) The Neural Crest, Cambridge University Press, Cambridge, England.

Le Douarin, N. M., and M. A. Teillet (1974) Experimental analysis of the migration and differentiation of neuroblasts of the autonomic nervous system and of neurectodermal mesenchymal derivatives, using a biological cell marking technique. Dev. Biol. 41: 162184.

Le Douarin, N. M., J. Smith, and C. S. Le Lièvre (1981) From the neural crest to the ganglia of the peripheral nervous system. Annu. Rev. Physiol. 43: 653-671.

Le Douarin, N. M., P. Cochard, M. Vincent, J. L. Duband, G. C. Tucker, M. A. Teillet, and J. P. Thiery (1983) Nuclear, cytoplasmic and membrane markers to follow neural crest cell migration: A comparative study. In The Role of Extracellular Matrix in Development, R. L. 'I'relstad, ed., Alan R. Liss, New York. In press.

Lowry, O. H., N. J. Rosebrough, A. L. Farr, and R. J. Randall (1951) Protein measurement with the Folin phenol reagent. J. Biol. Chem. 193: 265-275.

Lundberg, J. M., B. Hamberger, M. Schultzberg, T. Hökfelt, P. O. Granberg, S. Efendic, L. Terenius, M. Goldstein, and R. Iuft (1979) Finkephalin- and somatostatin-like immunoreactivities in human adrenal medulla and pheochromocytoma. Proc. Natl. Acad. Sci. U. S. A. 76: 4079-4083.

Lundberg, J. M., R. Hökfelt, A. Anggard, L. Terenius, R. Elde, K. Markey, M. Goldstein, and J. Kimmel (1982) Organizational principles in the peripheral nervous system: Subdivision by coexisting peptides (somatostatin-, avian pancreatic polipeptide- and vasoactive intestinal polypeptide-like immunoreactive materials). Proc. Natl. Acad. Sci. U. S. A. 79 .
1303-1307.

Maxwell, G. D., P. D. Sietz, and C. E. Rafford (1982) Synthesis and accumulation of putative neurotransmitters by cultured neural crest cells. J. Neurosci. 2: 879-888.

Maxwell, G. D., P. D. Sietz, and P. H. Chenard (1984) Development of somatostatin-like immunoreactivity in embryonic sympathetic ganglia. J. Neurosci. 4: 576-584.

Mizobe, F., V. Kozousek, D. M. Dean, and B. G. Livett (1979) Pharmacological characterization of adrenal paraneurons: Substance $\mathrm{P}$ and somatostatin as inhibitory modulators of the nicotinic response. Brain Res 178: 555-566.

Norr, S. C. (1973) In vitro analysis of sympathetic neuron differentiation from chick neural crest cells. Dev. Biol. 34. 16-38.

Patel, Y., and S. Reichlin (1978) Somatostatin in hypothalamus, extrahypothalamic brain and peripheral tissues of the rat. Endocrinology 102: 523-530.

Patterson, P. H. (1978) Environmental determination of autonomic neurotransmitter functions. Annu. Rev. Neurosci. 1: $1-17$.

Renaud, L. P., J. B. Martin, and P. Brazeau (1975) Depressant action of TRH, LH-RH and somatostatin on activity of central neurones. Nature 255: 233-235.

Role, L. W., S. E. Leeman, and R. L. Perlman (1981) Somatostatin and substance $\mathrm{P}$ inhibit catecholamine secretion from isolated cells of guinea-pig adrenal medulla. Neuroscience 6 : 1813-1821.

Romanoff, A. L. (1960) The Avian Embryo, Macmillan, New York.

Rothman, T. P., M. D. Gershon, and H. Holtzer (1978) The relationship of cell division to the acquisition of adrenergic characteristics by developing sympathetic ganglion cell precursors. Dev. Biol. 65: 322-341.

Smith, J., N. M. Le Douarin, M. Fauquet, and C. Ziller (1981) The development of autonomic neurons from the neural crest: In vivo and in vitro studies. In Development in the Nervous System, X. Garrod and X. Feldman, eds., Cambridge University Press, Cambridge, England.

Teillet, M. A., P. Cochard, and N. L. Le Douarin (1978) Relative roles of the mesenchymal tissues and of the complex neural tube-notochord on the expression of adrenergic metabolism in neural crest cells. Zoon 6: 115-122.

Ternynck, T., and S. Avrameas (1976) A new method using $p$ benzoquinone for coupling antigens and antibodies to marker substances. Ann. Immunol. 127: 197-208.

Thiery, J. P., J. L. Duband, and A. Delouvée (1982) Pathways and mechanisms of avian neural crest cells migration and localization. Dev. Biol. 93: 324-343.

Weston, J. A. (1970) The migration and differentiation of neural crest cells. Adv. Morphogen. 8: 41-114.

Yntema, C., and W. S. Hammond (1947) The development of the autonomic nervous system. Biol. Rev. 222: 344-359.

Zacchei, A. M. (1961) Lo sviluppo embrionale della quaglia giapponese (Coturnix coturnix japonica T.S.). Arch. Ital. Anat. Embriol. 66: 36-62. 